\title{
Effectiveness of bendamustine in relapsed or refractory lymphoma cases: a Turkish Oncology Group study
}

Nuri Karadurmus ${ }^{1}$, Semra Paydas², Ece Esin ${ }^{3}$, Zeki Gokhan Surmeli ${ }^{4}$, Birol Yildiz ${ }^{1}$, Ismail Erturk ${ }^{1}$, Erdinc Nayir ${ }^{4}$, Mutlu Dogan ${ }^{5}$, Ahmet Taner Sumbul ${ }^{6}$, Ibrahim Barista7, Emel Gurkan ${ }^{8}$, Ramazan Ocal ${ }^{9}$, Burhan Ferhanoglu ${ }^{10}$, Gokhan Ozgur ${ }^{11}$, Yusuf Karakas ${ }^{7}$, Sahin Lacin ${ }^{7}$, Sukru Ozaydin ${ }^{1}$, Halil Ibrahim Petekkaya ${ }^{12}$, Necdet Uskent ${ }^{13}$

${ }^{1}$ Department of Medical Oncology, Health Sciences University, Gulhane Training and Research Hospital, Ankara, Turkey

${ }^{2}$ Department of Medical Oncology, Faculty of Medicine, Cukurova University, Adana, Turkey

${ }^{3}$ Department of Medical Oncology, Health Sciences University, Dr. Abdurrahman Yurtaslan Training and Research Hospital, Ankara, Turkey

${ }^{4}$ Department of Medical Oncology, Medicalpark Hospital, Ankara, Turkey

${ }^{5}$ Department of Medical Oncology, Health Sciences University, Numune Training and Research Hospital, Ankara, Turkey

${ }^{6}$ Department of Medical Oncology, Faculty of Medicine, Baskent University, Adana, Turkey

${ }^{7}$ Department of Medical Oncology, Faculty of Medicine, Hacettepe University, Ankara, Turkey

${ }^{8}$ Department of Haematology, Faculty of Medicine, Cukurova University, Adana,

Turkey

${ }^{9}$ Department of Haematology, Faculty of Medicine, Gazi University, Ankara, Turkey

${ }^{10}$ Department of Haematology, Faculty of Medicine, Koc University, Istanbul, Turkey

${ }^{11}$ Department of Haematology, Health Sciences University, Gulhane Training and Research Hospital, Ankara, Turkey

${ }^{12}$ Department of Medical Oncology, Special Tinaztepe Hospital, Izmir, Turkey

${ }^{13}$ Department of Medical Oncology, Anatolian Health Center, Istanbul, Turkey

Submitted: 21 February 2018; Accepted: 7 August 2018

Online publication: 18 February 2019

Arch Med Sci 2021; 17 (4): 920-927

DOI: https://doi.org/10.5114/aoms.2019.83000

Copyright (c) 2019 Termedia \& Banach

\section{Abstract}

Introduction: We aimed to investigate the efficacy and side effects of bendamustine in relapsed/refractory lymphoma patients in Turkey.

Material and methods: In this retrospective study, we included relapsed/ refractory Hodgkin lymphoma $(\mathrm{HL})$ and non-Hodgkin lymphoma $(\mathrm{NHL})$ patients who underwent multiple lines of chemotherapy. The primary endpoint was to determine the objective response and toxicity.

Results: Ninety-nine patients with a median age of 59.8 years were included in the study. Eighty-one patients had NHL (follicular lymphoma: 10, diffuse large B-cell lymphoma: 27, mantle-cell lymphoma: 18, marginal zone lymphoma: 9, small lymphocytic lymphoma/chronic lymphocytic leukemia: 17) and 18 patients had HL. The patients had previously received a median of three lines of chemotherapy (range: $2-8$ ) except autologous stem cell transplantation (ASCT); 19 patients (HL: 11, NHL: 8) had undergone ASCT. The objective response rate (ORR) was $74.3 \%$, the complete response rate was $57 \%$ $(=53)$, and the partial response rate was $16.6 \%(=19)$. The overall survival (OS) rate at 1 year was $74.6 \%$. The progression-free survival (PFS) rate at 1 year was $62.5 \%$. The most common side effects were lymphopenia, anemia and neutropenia. Side effects which were observed as grade 3 and higher levels were lymphopenia (14.1\%), neutropenia (10.1\%) and fatigue (7.1\%).

\section{Corresponding author:} Ismail Erturk PhD

Department of Medical Oncology Health Sciences University Gulhane Training and Research Hospital 06230 Ankara, Turkey Phone: +90 5058726378

E-mail: ierturk@hotmail.com 
Conclusions: Objective response rate of bendamustine was found to be $74.3 \%$ in relapsed/refractory $\mathrm{HL}$ and $\mathrm{NHL}$ patients. It appears to be an effective option as a salvage treatment for patients who have previously received multiple lines of therapy.

Key words: bendamustine, lymphoma, Hodgkin lymphoma.

\section{Introduction}

Non-Hodgkin lymphoma (NHL) consists of malignant neoplasms of the lymphoid tissues derived from progenitor or mature B, T, and NK cells [1]. The other malign neoplasms derived from lymphoid tissue are chronic lymphocytic leukemia (CLL) and Hodgkin lymphoma (HL). Most patients with these neoplasms attain complete remission after an initial treatment and achieve long-term disease control. However, relapse may eventually occur in some of the patients. Moreover, some patients can have refractory disease that either does not respond to initial therapy or progresses after an initial response. Treatment options for lymphomas consist of chemotherapy, immunotherapy, radiation therapy, or a combination of these [2]. A subset of patients, who are relapsed or refractory, is treated with high-dose chemotherapy followed by stem cell transplantation. Currently, there is no standard salvage chemotherapy regimen for relapsed/refractory NHL, HL, and CLL, and clinical practice at this point is highly variable [3]. Toxicity of conventional salvage chemotherapy regimens are substantial, and patient comorbidities may influence the selection of a particular chemotherapeutic regimen for each case.

Bendamustine is a cytotoxic compound which was synthesized as a hybrid molecule intended to combine the activities of the purine antimetabolite benzimidazole [4]. Most importantly, bendamustine exhibits only partial cross resistance with other alkylators, making it a treatment of choice for relapsed/refractory patients [5]. Bendamustine is indicated for the treatment of CLL and B cell $\mathrm{NHL}$ progressing within 6 months of treatment with rituximab monotherapy or a rituximab-containing regimen $[6,7]$.

In order to assess the efficacy of bendamustine outside clinical trials, we conducted a retrospective study in patients with relapsed/refractory lymphoid malignancies treated with bendamustine. Although the efficacy and safety of bendamustine had been examined in several clinical trials, this was the first study to evaluate its efficacy and safety in a Turkish cohort.

\section{Material and methods}

Data were retrospectively collected from medical records of patients treated in nine oncology centers in Turkey. All patients treated with at least one cycle of bendamustine alone or in combina- tion with rituximab for histologically confirmed recurrent or refractory lymphoma between $1^{\text {st }}$ January 2011 and $1^{\text {st }}$ January 2017 were included. Eligible histological diagnoses were diffuse large B-cell lymphoma (DLBCL), follicular lymphoma $(\mathrm{FL})$, mantle cell lymphoma $(\mathrm{MCL})$, marginal zone lymphoma (MZL), chronic lymphocytic leukemia/small lymphocytic lymphoma (CLL/SLL) and Hodgkin lymphoma ( $\mathrm{HL})$. Response assessments were performed based on radiological imaging results and physical examination records. Physician notes, hospital admissions and results of laboratory test that were performed before every treatment cycle were reviewed for adverse events graded according to National Cancer Institute Common Terminology Criteria for Adverse Events (NCl-CTCAE) version 4.0. This study was approved by the institutional ethics committee of Gulhane School of Medicine.

\section{Statistical analysis}

Considering the clinical heterogeneity of histological subtypes, efficacy results were reported separately for each histological subtype. Continuous variables were summarized as median and interquartile range (quartiles 1 to 3), and categorical variables were summarized as counts and percentages. Progression-free survival (PFS) and overall survival (OS) estimates were calculated with the Kaplan-Meier method. The PFS was defined as the interval between the initiation of bendamustine and recurrence or death from any cause. The OS was measured from the initiation of bendamustine to death from any cause. Statistical analyses were performed with the SPSS software (PASW Statistics for Windows, version 18.0, Chicago, SPSS Inc.).

\section{Results}

\section{Patient characteristics}

A total of 99 patients who received bendamustine for relapsed or refractory lymphoma were included. Of those, 27 patients had DLBCL, 18 patients had MCL, 18 patients had HL, 17 patients had CLL/SLL, 10 patients had FL, and 9 patients had MZL. Baseline characteristics of the patients are shown in Table I. Median age was 28.2 years in patients with $\mathrm{HL}$ and 71.4 years in patients with DLBCL. Patients generally received bendamustine as third-line treatment in DLBCL, FL, and CLL/SLL groups; as second-line treatment in MCL and MZL 
N. Karadurmus, S. Paydas, E. Esin, Z.G. Surmeli, B. Yildiz, I. Erturk, E. Nayir, M. Dogan, A.T. Sumbul, I. Barista, E. Gurkan, R. Ocal, B. Ferhanoglu, G. Ozgur, Y. Karakas, S. Lacin, S. Ozaydin, H.I. Petekkaya, N. Uskent

Table I. Patient characteristics

\begin{tabular}{|c|c|c|c|c|c|c|c|c|c|c|c|c|}
\hline \multirow{2}{*}{$\begin{array}{l}\text { Parameter } \\
\text { Total, } n(\%)\end{array}$} & \multicolumn{2}{|c|}{ DLBCL } & \multicolumn{2}{|c|}{$\mathrm{FL}$} & \multicolumn{2}{|c|}{$M C L$} & \multicolumn{2}{|c|}{ MZL } & \multicolumn{2}{|c|}{ CLL/SLL } & \multicolumn{2}{|c|}{$\mathrm{HL}$} \\
\hline & 27 & $(100)$ & 10 & $(100)$ & 18 & $(100)$ & 9 & $(100)$ & 17 & $(100)$ & 18 & $(100)$ \\
\hline \multicolumn{13}{|l|}{ Age [years]: } \\
\hline Median & \multicolumn{2}{|c|}{71.4} & \multicolumn{2}{|c|}{66.9} & \multicolumn{2}{|c|}{65.6} & \multicolumn{2}{|c|}{62.7} & \multicolumn{2}{|c|}{64} & \multicolumn{2}{|c|}{28.2} \\
\hline Range & \multicolumn{2}{|c|}{$(27-89)$} & \multicolumn{2}{|c|}{$(49-82)$} & \multicolumn{2}{|c|}{$(49-79)$} & \multicolumn{2}{|c|}{$(45-78)$} & \multicolumn{2}{|c|}{$(37-85)$} & \multicolumn{2}{|c|}{$(16-72)$} \\
\hline \multicolumn{13}{|l|}{ Gender, $n$ (\%): } \\
\hline Male & 15 & $(55.6)$ & 6 & $(60)$ & 15 & (83.3) & 3 & (33.3) & 13 & $(76.5)$ & 13 & $(72.2)$ \\
\hline Female & 12 & $(44.4)$ & 4 & $(40)$ & 3 & $(16.7)$ & 6 & $(66.7)$ & 4 & $(23.5)$ & 5 & $(27.8)$ \\
\hline \multicolumn{13}{|l|}{ Stage at diagnosis: } \\
\hline | or II & 8 & $(29.6)$ & 0 & (0) & 2 & $(11.1)$ & 3 & (33.3) & 8 & $(47.1)$ & 5 & $(27.8)$ \\
\hline III or IV & 19 & $(70.3)$ & 10 & $(100)$ & 16 & (88.9) & 6 & $(66.7)$ & 9 & $(52.9)$ & 13 & $(72.2)$ \\
\hline Bulky disease at $d$ & & & & & & & & & & & & \\
\hline Present & 9 & $(33.3)$ & 1 & $(10)$ & 4 & $(22.2)$ & 2 & $(22.2)$ & 5 & $(29.4)$ & 5 & $(27.8)$ \\
\hline Extranodal disease & & & & & & & & & & & & \\
\hline Present & 9 & $(33.3)$ & 6 & $(60)$ & 10 & $(55.6)$ & 7 & (77.8) & 4 & $(23.5)$ & 6 & (33.3) \\
\hline ECOG status, $n$ (\% & & & & & & & & & & & & \\
\hline 0 or 1 & 14 & $(51.9)$ & 7 & $(70)$ & 11 & (61.1) & 7 & (77.8) & 13 & $(76.5)$ & 16 & $(88.9)$ \\
\hline 2 or 3 & 13 & $(48.1)$ & 3 & $(30)$ & 7 & (38.9) & 2 & $(22.2)$ & 4 & $(23.5)$ & 2 & $(11.1)$ \\
\hline B symptoms, $n$ (\% & & & & & & & & & & & & \\
\hline Present & 7 & $(25.9)$ & 3 & (30) & 4 & $(22.2)$ & 4 & $(44.4)$ & 7 & $(41.2)$ & 13 & $(68.5)$ \\
\hline $\begin{array}{l}\text { Refractory to previ } \\
\text { chemotherapy: }\end{array}$ & & & & & & & & & & & & \\
\hline Yes & 15 & $(55.6)$ & 2 & $(22.2)$ & 9 & (50) & 2 & $(22.2)$ & 3 & $(18.8)$ & 12 & $(66.7)$ \\
\hline Disease duration* & & & & & & & & & & & & \\
\hline Median & & 4.5 & & 9.2 & & 2.8 & & 2.2 & & 4.2 & & 6.6 \\
\hline Range & & $-140)$ & & 148) & & $-67)$ & & 158) & & $-114)$ & & $-114)$ \\
\hline Previous treatmen & & & & & & & & & & & & \\
\hline Rituximab & 27 & $(100)$ & 9 & $(90)$ & 14 & (77.8) & 8 & (88.9) & 14 & $(82.4)$ & 0 & (0) \\
\hline$A B V D$ & 0 & (0) & 0 & (0) & 0 & (0) & 0 & (0) & 0 & (0) & 17 & $(94.4)$ \\
\hline $\mathrm{CHOP}$ & 25 & $(92.6)$ & 7 & $(70)$ & 12 & (66.7) & 3 & (33.3) & 6 & $(35.3)$ & 0 & (0) \\
\hline $\mathrm{FC}$ & 1 & (3.7) & 2 & $(20)$ & 0 & (0) & 0 & (0) & 11 & $(64.7)$ & 0 & (0) \\
\hline CVP & 4 & $(14.8)$ & 3 & (30) & 3 & (16.7) & 3 & (33.3) & 6 & (35.3) & 1 & $(5.6)$ \\
\hline DHAP & 0 & (0) & 0 & (0) & 3 & (16.7) & 0 & (0) & 0 & (0) & 10 & $(55.6)$ \\
\hline ICE & 8 & $(29.6)$ & 1 & $(10)$ & 3 & (16.7) & 0 & (0) & 1 & (5.9) & 9 & (50) \\
\hline Other & 13 & $(48.1)$ & 1 & $(10)$ & 8 & (44.4) & 0 & (0) & 2 & (11.8) & 12 & $(66.7)$ \\
\hline Radiotherapy & 11 & $(40.7)$ & 4 & $(40)$ & 3 & $(16.7)$ & 1 & (11.1) & 0 & (0) & 6 & (33.3) \\
\hline Autologous SCT & 1 & (3.7) & 2 & $(20)$ & 5 & $(27.8)$ & 0 & (0) & 0 & (0) & 11 & $(61.1)$ \\
\hline Treatment setting, & & & & & & & & & & & & \\
\hline $2^{\text {nd }}$-line & 10 & (37) & 4 & $(40)$ & 9 & (53) & 8 & $(80)$ & 8 & $(47.1)$ & 1 & $(5.6)$ \\
\hline $3^{\text {rd-line }}$ & 12 & $(44.4)$ & 2 & $(20)$ & 5 & $(29.4)$ & 1 & (10) & 7 & $(41.2)$ & 1 & $(5.6)$ \\
\hline Beyond $3^{\text {rd }}$-line & 5 & $(18.5)$ & 4 & $(40)$ & 3 & $(17.6)$ & 1 & (10) & 2 & $(11.8)$ & 16 & $(88.8)$ \\
\hline Median & & 3 & & 3 & & 2 & & 2 & & 3 & & 5 \\
\hline Range & & $2-6)$ & & $-5)$ & & $-5)$ & & $-7)$ & & $2-5)$ & & $2-8)$ \\
\hline
\end{tabular}

The percentages in parentheses are column percentages. *Disease duration refers to the time from initial diagnosis of lymphoma to the initiation of study treatment. ABVD - Adriamycin, bleomycin, vinblastine, dacarbazine, CHOP-cyclophosphamide, doxorubicin, vincristine, prednisone, CLL/SLL - chronic lymphocytic lymphoma/small lymphocytic lymphoma, CVP - cyclophosphamide, vincristine, prednisone, DHAP - dexamethasone, cytarabine, cisplatin, DLBCL - diffuse large B-cell lymphoma, ECOG - Eastern Cooperative Oncology Group, FC - fludarabine, cyclophosphamide, FL - follicular lymphoma, HL - Hodgkin lymphoma, ICE - ifosfamide, carboplatin, etoposide, $M C L$ - mantle-cell lymphoma, MZL - marginal zone lymphoma, SCT - stem cell transplantation. 
patients; and as fifth-line treatment in patients with HL. Patient demographics and disease characteristics are summarized in Table I.

\section{Treatment exposure and efficacy}

Patients received a median of 4 cycles of bendamustine in the DLBCL group and 6 cycles in other groups (Table II). A total of 538 cycles of benda- mustine were administered. The median duration of bendamustine treatment ranged from 4.5 (in the DLBCL group) to 5.6 months (in the MCL group). The most commonly preferred schedule was $90 \mathrm{mg} / \mathrm{m}^{2}$ administered every three weeks. Objective response rates were $55.6 \%$ in DLBCL, $61.1 \%$ in $\mathrm{HL}, 72.2 \%$ in MCL, 80\% in FL, 88.2\% in CLL/SLL, and $88.9 \%$ in MZL patients (Table III). The majority of

Table II. Treatment exposure

\begin{tabular}{|c|c|c|c|c|c|c|}
\hline Parameter & DLBCL $(n=27)$ & $\mathrm{FL}(n=10)$ & MCL $(n=18)$ & MZL $(n=9)$ & CLL/SLL $(n=17)$ & $\mathrm{HL}(n=18)$ \\
\hline \multicolumn{7}{|c|}{ Treatment duration [months]: } \\
\hline Median & 4.5 & 5.3 & 5.6 & 4.9 & 5.3 & 5.3 \\
\hline Range & $(0.7-37.3)$ & $(1.7-7.6)$ & $(1.7-28.7)$ & $(1.6-6.4)$ & $(3.6-9)$ & $(0.3-22)$ \\
\hline \multicolumn{7}{|l|}{ No. of cycles: } \\
\hline Median & 4 & 6 & 6 & 6 & 6 & 6 \\
\hline Range & $(1-8)$ & $(2-9)$ & $(2-38)$ & $(2-8)$ & $(4-6)$ & $(1-10)$ \\
\hline \multicolumn{7}{|c|}{ Bendamustine dosage, $n(\%)$ : } \\
\hline $90 \mathrm{mg} / \mathrm{m}^{2}$ & (63) & $(80)$ & $(88.9)$ & $(100)$ & (100) & $(77.8)$ \\
\hline $100 \mathrm{mg} / \mathrm{m}^{2}$ & (33.3) & (20) & $(11.1)$ & (0) & (0) & (5.6) \\
\hline $120 \mathrm{mg} / \mathrm{m}^{2}$ & $(3.7)$ & (0) & (0) & (0) & (0) & $(16.7)$ \\
\hline
\end{tabular}

Note: The percentages in parentheses are column percentages. CLL/SLL - chronic lymphocytic lymphoma/small lymphocytic lymphoma, $D L B C L$-diffuse large B-cell lymphoma, FL - follicular lymphoma, $H L$ - Hodgkin lymphoma, MCL - mantle cell lymphoma, MZL - marginal zone lymphoma.

Table III. Efficacy results

\begin{tabular}{|c|c|c|c|c|c|c|c|c|c|c|c|c|}
\hline \multirow{2}{*}{\begin{tabular}{|l|} 
Parameter \\
Best response, $n(\%)$ :
\end{tabular}} & \multicolumn{2}{|c|}{$\begin{array}{c}\text { DLBCL } \\
(n=27)\end{array}$} & \multicolumn{2}{|c|}{$\begin{array}{c}\mathrm{FL} \\
(n=10)\end{array}$} & \multicolumn{2}{|c|}{$\begin{array}{c}\text { MCL } \\
(n=18)\end{array}$} & \multicolumn{2}{|c|}{$\begin{array}{c}\text { MZL } \\
(n=9)\end{array}$} & \multicolumn{2}{|c|}{$\begin{array}{l}\text { CLL/SLL } \\
(n=17)\end{array}$} & \multicolumn{2}{|c|}{$\begin{array}{c}\mathrm{HL} \\
(n=18)\end{array}$} \\
\hline & & & & & & & & & & & & \\
\hline Complete response & 12 & $(44.4)$ & 6 & $(60)$ & 11 & $(61.1)$ & 8 & $(88.9)$ & 9 & (52.9) & 7 & $(38.8)$ \\
\hline Partial response & 3 & $(11.1)$ & 2 & (20) & 2 & $(11.1)$ & 0 & (0) & 6 & (35.3) & 4 & $(22.2)$ \\
\hline Stable disease & 3 & (11.1) & 0 & (0) & 2 & $(11.1)$ & 0 & (0) & 1 & (5.9) & 5 & $(27.8)$ \\
\hline Progressive disease & 8 & $(29.6)$ & 2 & (20) & 2 & $(11.1)$ & 1 & $(11.1)$ & 0 & (0) & 1 & $(5.6)$ \\
\hline Unknown & 1 & (3.7) & 0 & (0) & 1 & $(5.6)$ & 0 & (0) & 1 & (5.9) & 1 & (5.6) \\
\hline ORR, \% $(95 \% \mathrm{Cl})$ & \multicolumn{2}{|c|}{$\begin{array}{c}55.6 \\
(35.3-74.5)\end{array}$} & \multicolumn{2}{|c|}{$\begin{array}{c}80 \\
(44.4-97.5)\end{array}$} & \multicolumn{2}{|c|}{$\begin{array}{c}72.2 \\
(46.5-90.3)\end{array}$} & \multicolumn{2}{|c|}{$\begin{array}{c}88.9 \\
(51.8-99.7)\end{array}$} & \multicolumn{2}{|c|}{$\begin{array}{c}88.2 \\
(63.6-98.5)\end{array}$} & \multicolumn{2}{|c|}{$\begin{array}{c}61.1 \\
(38.6-79.7)\end{array}$} \\
\hline \multicolumn{13}{|l|}{ Progression-free survival: } \\
\hline No. of events & \multicolumn{2}{|c|}{13} & \multicolumn{2}{|r|}{7} & \multicolumn{2}{|c|}{8} & \multicolumn{2}{|r|}{2} & \multicolumn{2}{|r|}{5} & \multicolumn{2}{|r|}{9} \\
\hline $\begin{array}{l}\text { 1-year PFS, \% } \\
(95 \% \mathrm{Cl})\end{array}$ & \multicolumn{2}{|c|}{$\begin{array}{c}43 \\
(21.1-63.3)\end{array}$} & \multicolumn{2}{|c|}{$\begin{array}{c}50 \\
(18.4-75.3)\end{array}$} & \multicolumn{2}{|c|}{$\begin{array}{c}63.9 \\
(36.5-82)\end{array}$} & \multicolumn{2}{|c|}{$\begin{array}{c}71.4 \\
(25.8-92)\end{array}$} & \multicolumn{2}{|c|}{$\begin{array}{c}85.7 \\
(53.9-96.2)\end{array}$} & \multicolumn{2}{|c|}{$\begin{array}{c}61.1 \\
(35.3-79.2)\end{array}$} \\
\hline $\begin{array}{l}\text { 2-year PFS, \% } \\
(95 \% \mathrm{CI})\end{array}$ & \multicolumn{2}{|c|}{$\begin{array}{c}43 \\
(21.1-63.3)\end{array}$} & \multicolumn{2}{|c|}{$\begin{array}{c}40 \\
(12.3-67)\end{array}$} & \multicolumn{2}{|c|}{$\begin{array}{c}53.3 \\
(24.3-75.6)\end{array}$} & \multicolumn{2}{|c|}{$\begin{array}{c}71.4 \\
(25.8-92)\end{array}$} & \multicolumn{2}{|c|}{$\begin{array}{c}55.1 \\
(22-79)\end{array}$} & \multicolumn{2}{|c|}{$\begin{array}{c}45.8 \\
(20.9-67.8)\end{array}$} \\
\hline $\begin{array}{l}\text { Median PFS [months] } \\
(95 \% \mathrm{Cl})\end{array}$ & \multicolumn{2}{|c|}{$\begin{array}{c}11.1 \\
(5.5-16.7)\end{array}$} & \multicolumn{2}{|c|}{$\begin{array}{c}8.6 \\
(0-17.9)\end{array}$} & $\begin{array}{r}2 \\
(3.1 \\
\end{array}$ & $\begin{array}{l}5.9 \\
-48.6)\end{array}$ & & NE & & NE & & $\begin{array}{l}3.2 \\
\text { NE) }\end{array}$ \\
\hline Overall survival: & & & & & & & & & & & & \\
\hline No. of events & & 12 & & 3 & & 5 & & 2 & & 3 & & 6 \\
\hline $\begin{array}{l}1 \text {-year OS, \% } \\
(95 \% \mathrm{CI})\end{array}$ & $(25$ & $\begin{array}{l}48.2 \\
3-67.9)\end{array}$ & (43. & $\begin{array}{l}.9 \\
98.4)\end{array}$ & $\begin{array}{r}{ }^{7} \\
(45 .)^{2}\end{array}$ & $\begin{array}{l}4.9 \\
-89.9)\end{array}$ & $(25$ & $\begin{array}{l}71.4 \\
.8-92)\end{array}$ & & $\begin{array}{l}92.9 \\
.1-99)\end{array}$ & (47. & $\begin{array}{l}1.8 \\
2-87.9)\end{array}$ \\
\hline $\begin{array}{l}\text { 2-year OS, \% } \\
(95 \% \mathrm{CI})\end{array}$ & $(25$ & $\begin{array}{l}41.3 \\
3-67.9)\end{array}$ & (33. & $\begin{array}{l}6.2 \\
-93.5)\end{array}$ & $\begin{array}{r}7 \\
(45 .)^{7}\end{array}$ & $\begin{array}{l}4.9 \\
-89.9)\end{array}$ & & $\begin{array}{l}71.4 \\
.8-92)\end{array}$ & & $\begin{array}{l}73.9 \\
.9-91)\end{array}$ & & $\begin{array}{l}4.6 \\
-82.5)\end{array}$ \\
\hline
\end{tabular}

Note: The percentages in parentheses are column percentages. $\mathrm{Cl}$ - confidence interval, CLL/SLL - chronic lymphocytic lymphomal small lymphocytic lymphoma, DLBCL - diffuse large B-cell lymphoma, FL - follicular lymphoma, HL - Hodgkin lymphoma, $M C L$ - mantle cell lymphoma, MZL - marginal zone lymphoma, NE - not estimable, ORR - objective response rate, OS - overall survival, PFS - progression-free survival. 
N. Karadurmus, S. Paydas, E. Esin, Z.G. Surmeli, B. Yildiz, I. Erturk, E. Nayir, M. Dogan, A.T. Sumbul, I. Barista, E. Gurkan, R. Ocal, B. Ferhanoglu, G. Ozgur, Y. Karakas, S. Lacin, S. Ozaydin, H.I. Petekkaya, N. Uskent

the responses were complete responses ranging from $38.8 \%$ in $\mathrm{HL}$ to $88.9 \%$ in MZL patients (Table III). At a median follow-up of 22 months, the estimates of 1 -year PFS were $43 \%$ in DLBCL, $50 \%$ in $\mathrm{FL}, 61.1 \%$ in $\mathrm{HL}, 64.6 \%$ in $\mathrm{MCL}, 71.4 \%$ in $\mathrm{MZL}$, and $85.7 \%$ in CLL/SLL groups; and the estimates of 1 -year OS were $48.2 \%$ in DLBCL, $71.4 \%$ in MZL, $71.8 \%$ in $\mathrm{HL}, 74.9 \%$ in $\mathrm{MCL}, 88.9 \%$ in $\mathrm{FL}$, and $92.9 \%$ in CLL/SLL (Table III, Figure 1).

After bendamustine treatment, stem cell transplantation (SCT) was performed in $8 \%$ of patients who had at least a partial response. Autologous SCT was performed in 6 patients and two of them had CR (one DLBCL and one $\mathrm{HL}$ ). Allogeneic SCT was performed in two $\mathrm{HL}$ patients who achieved CR with bendamustine. Details of bendamustine efficacy in bridging to SCT and rates of SCT are shown in Table IV.

\section{Safety and adverse events}

Hematological adverse events associated with bendamustine were common but usually low grade; the incidence of lymphopenia, anemia, neutropenia and thrombocytopenia was $74.7 \%$,

A

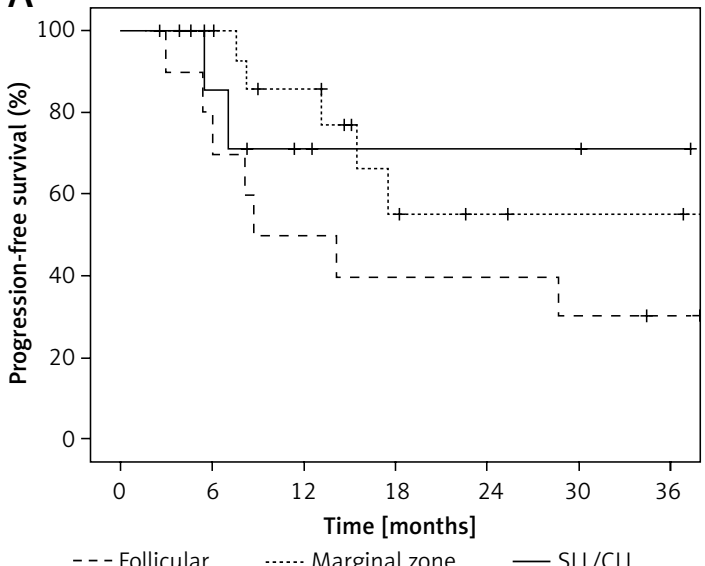

C

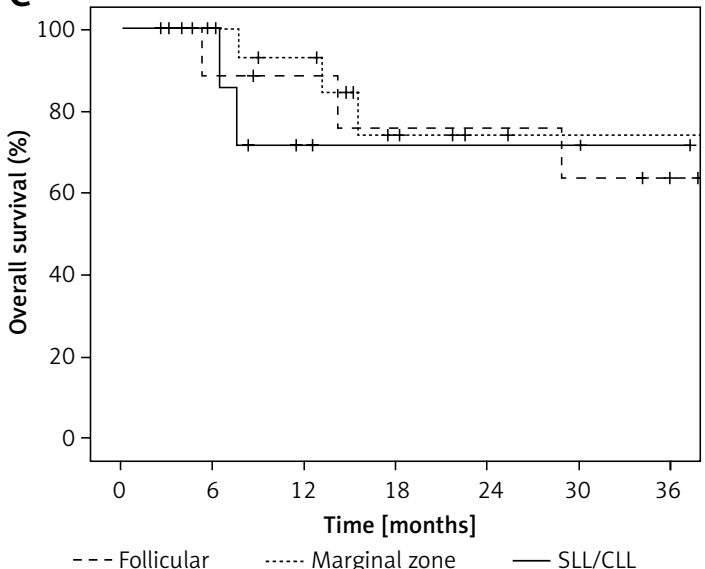

$64.6 \%, 61.6 \%$, and $45.5 \%$, respectively (Table V). Nausea and diarrhea were observed in $41.4 \%$ and $27.3 \%$ of the patients. Other toxicities were elevat ed alanine aminotransferase (25.2\%), peripheral edema (22.2\%), elevated aspartate aminotransferase (21.2\%), rash (17.2), and alopecia (15.1\%). At least one dose delay or dose reduction was required in $25.3 \%$ and $11.1 \%$ of patients, respectively. Adverse events did not necessitate treatment discontinuation in any patients. No deaths were attributed to bendamustine treatment. At a median follow-up duration of 22 months no secondary malignancies have been recorded.

\section{Discussion}

Bendamustine is a bimodal chemotherapeutic agent having both alkylating and antimetabolite properties. The combined cytotoxic activity of bendamustine has resulted in high response rates and durable responses in patients with heavily pretreated indolent and aggressive lymphomas. This study presents the longitudinal multicenter results of bendamustine in heavily pretreated in dolent B-NHL, DLBCL and HL patients. In our study,

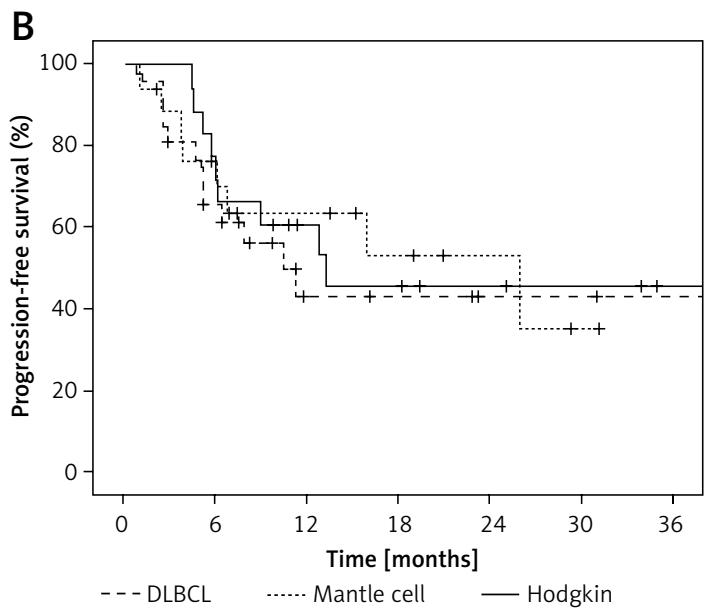

D

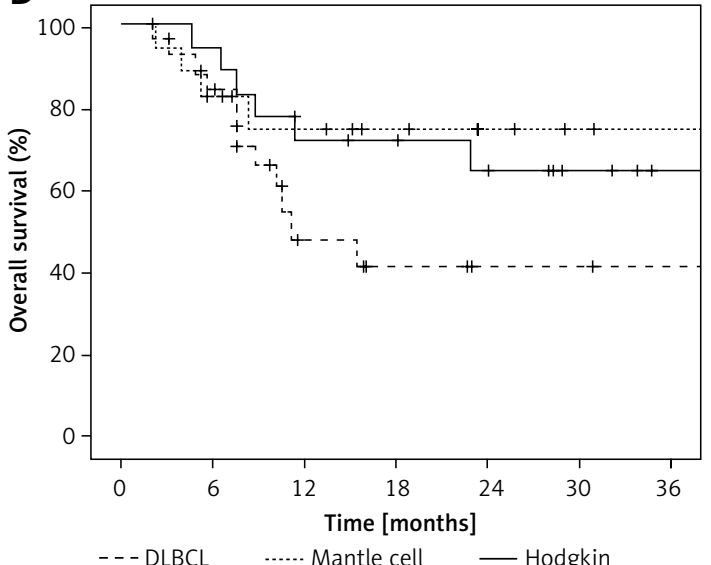

Figure 1. Progression-free (A, B) and overall survival (C, D) curves with bendamustine treatment in histological subtypes of relapsed/refractory lymphoma

DLBCL-diffuse large B-cell lymphoma, SLL/CLL - small lymphocytic lymphoma/chronic lymphocytic leukemia. 
Table IV. Post-bendamustine stem cell transplantation rates

\begin{tabular}{|c|c|c|c|c|c|}
\hline SCT & Lymphoma type & $N$ & $\%$ & $\begin{array}{l}\text { Bendamustine dose }\left[\mathrm{mg} / \mathrm{m}^{2}\right] \\
\text { and number of cycles }\end{array}$ & $\begin{array}{l}\text { Post-bendamustine } \\
\text { response }\end{array}$ \\
\hline \multirow[t]{5}{*}{ Autologous } & Total & 6 & & & \\
\hline & $\mathrm{HL}$ & 3 & & $90-90-120 / 4-9-4$ & $1 \mathrm{CR}$ and 2 PR \\
\hline & $\mathrm{FL}$ & 1 & & $90 / 2$ & PR \\
\hline & DLBCL & 1 & & $100 / 8$ & $C R$ \\
\hline & $M C L$ & 1 & & $90 / 4$ & PR \\
\hline \multirow[t]{2}{*}{ Allogeneic } & Total & 2 & 1 & & \\
\hline & $\mathrm{HL}$ & 2 & & $100-90 / 4$ & $C R$ \\
\hline
\end{tabular}

$D L B C L-C R$ - complete response, diffuse large B-cell lymphoma, $F L$ - follicular lymphoma, HL - Hodgkin lymphoma, MCL - mantle-cell lymphoma, $P R$ - partial response, SCT - stem cell transplantation.

Table V. Adverse events

\begin{tabular}{|c|c|c|c|c|}
\hline \multirow[t]{2}{*}{ Adverse event* } & \multicolumn{3}{|c|}{ Any grade } & \multirow{2}{*}{$\begin{array}{c}\text { Grade } 3 \text { or } 4(\%) \\
(n=99)\end{array}$} \\
\hline & $\begin{array}{l}\text { All (\%) } \\
(n=99)\end{array}$ & $\begin{array}{l}\text { Among responders (\%) } \\
\qquad(n=70)\end{array}$ & $\begin{array}{c}\text { Among } \\
\text { non-responders (\%) } \\
(n=29)\end{array}$ & \\
\hline Lymphopenia & $74(74.7)$ & $53(75.7)$ & $21(72.4)$ & $14(14.1)$ \\
\hline Anemia & $64(64.6)$ & $43(61.4)$ & $21(72.4)$ & $5(5.1)$ \\
\hline Neutropenia & $61(61.6)$ & $47(67.1)$ & $14(48.3)$ & $10(10.1)$ \\
\hline Fatigue & $50(50.5)$ & $39(55.7)$ & 11 (37.9) & $7(7.1)$ \\
\hline Thrombocytopenia & $45(45.5)$ & $31(44.3)$ & $14(48.3)$ & $5(5.1)$ \\
\hline Nausea & $41(41.4)$ & $29(41.4)$ & $12(41.4)$ & $2(2)$ \\
\hline Diarrhea & $27(27.3)$ & $19(27.1)$ & $8(27.6)$ & $1(1)$ \\
\hline Elevated ALT & $25(25.2)$ & $16(22.9)$ & $9(31)$ & $1(1)$ \\
\hline Peripheral edema & $22(22.2)$ & $16(22.9)$ & $6(20.7)$ & $0(0)$ \\
\hline Elevated AST & $21(21.2)$ & $14(20)$ & $7(24.1)$ & $0(0)$ \\
\hline Rash & $17(17.2)$ & $12(17.1)$ & $5(17.2)$ & $0(0)$ \\
\hline Alopecia & $15(15.1)$ & $13(18.6)$ & $2(6.9)$ & NA \\
\hline
\end{tabular}

${ }^{\star}$ Adverse events observed in $15 \%$ or more of the patients, and grade 3 or 4 adverse events observed in $2 \%$ or more of the patients are listed. ALT - alanine aminotransferase, AST - aspartate aminotransferase.

there were 99 patients with diverse histologies and defined by their primary oncologist/hematologist as refractory patients. Hence, the results are important in terms of a possible treatment option in a patient group with dismal prognosis.

The number of cycles of administered bendamustine, treatment duration, dose intensity and the median number of previous chemotherapy regimens are the important parameters in terms of bendamustine efficacy. Median administered number of cycles [8-11] and median duration of treatment (4.5-5.6 months) were comparable with the accepted dose intensity [9-11]. The bendamustine dose was 90 to $120 \mathrm{mg} / \mathrm{m}^{2}$ per cycle and more than $80 \%$ of indolent lymphoma patients received $90 \mathrm{mg} / \mathrm{m}^{2}$ as compared to $37 \%$ of DLBCL patients who received at least $100 \mathrm{mg} / \mathrm{m}^{2}$. None of our patients was scheduled for lower doses of bendamustine (such as $60 \mathrm{mg} / \mathrm{m}^{2}$ ). The median number of prior regimens administered was two for indolent B-NHL, three for DLBCL, and five for $\mathrm{HL}$.
These results were found to be similar to the results of Ghesquieres et al. and Ohmachi et al. [11, 12]. However, our HL patient population was more heavily pre-treated than the others. None of the patients required discontinuation of treatment due to adverse events.

In this trial, ORR was found as $55.6 \%$ in patients with heavily pretreated DLBCL with the combination of bendamustine and rituximab. The estimated 1-year PFS and OS were found to be $43 \%$ and $48.2 \%$. These results are comparable with the results of more aggressive R-ESHAP and $\mathrm{R}$-ICE regimens. Although our patient population was refractory, the ORR, PFS, and OS data were found to be similar with the results of previous reports covering non-refractory cases $[13,14]$. In a small study including relapsed but not refractory cases with DLBCL, ORR was reported as 57\% [15]. Horn et al. reported a 55\% response rate in cases similar to our population composed of $75 \%$ DLBCL [16]. The highest success rate with bendamustine 
in refractory $D L B C L$ patients has been reported in a phase II trial and the response rate was 63\% [17].

Authors from Memorial Sloan Kettering Cancer Center reported an $53 \%$ ORR in cases with relapsed HL [18]. ORR with bendamustine as a single agent has been reported between 50 and 53\% in cases with refractory $\mathrm{HL}[10,11,19]$. Although the duration of response was short with a median PFS of 5 months, favorable treatment results were achieved in $\mathrm{HL}$. In our study ORR was $61.1 \%$ with an estimated 1 -year survival of $61.1 \%$ and 1 -year estimated OS was $71.8 \%$. AutoSCT and alloSCT were performed in 2 patients who were heavily pretreated (median 5 lines) and these 2 cases were more refractory than the previously reported cases.

Besides the efficacy of bendamustine in high grade $D L B C L$ and refractory $H L$, bendamustine is a salutary treatment agent in low grade lymphomas and MCL. Earlier studies and German group trials showed favorable single agent bendamustine activity in $\operatorname{CLL}[20,21]$. Later on, Fischer reported $45 \%$ and $60 \%$ response rates in 78 cases with CLL in fludarabine refractory and naive patients, respectively [16]. The median event-free survival observed by the German group was 14.7 months. In our study group, bendamustine was used as a median fourth line agent in CLL patients, ORR was $88.2 \%$, and estimated 1-year PFS and OS were 85.7 and $92.9 \%$, respectively. These results show the success of bendamustine treatment in refractory CLL/SLL patients.

The efficacy of bendamustine has also been analyzed in rituximab pre-treated or refractory patients with indolent B-cell lymphomas and FL and ORR has been found between $71 \%$ and $86 \%[12,14$, 22-25]. In our study ORR was $72.2 \%$ in MCL, $80 \%$ in FL and $88.9 \%$ in MZL patients. A complete response was detected in $88.9 \%$ of MZL patients. At a median follow-up of 22 months, 1-year PFS was $50 \%$ in $\mathrm{FL}, 64.6 \%$ in $\mathrm{MCL}$ and $71.4 \%$ in MZL; and 1 -year OS was $71.4 \%$ in MZL, $74.9 \%$ in MCL, and $88.9 \%$ in $\mathrm{FL}$. Although our patient population is heterogeneous regarding its characteristics, the main shared feature is the refractoriness and relapse rates, which are important for determining the importance of ORR and event-free survival rates.

The major toxicities observed with bendamustine were reversible myelosuppression, infections and gastrointestinal adverse events [9, 26]. Reported infections were recurring herpes zoster infections and cytomegalovirus infections $[9,22,25,27]$. Bendamustine was well tolerated in our patients and was not directly connected to life-threatening adverse events. Although adverse events were frequent, grade III-IV toxicity was low; namely $1 \%$ diarrhea and $14 \%$ lymphopenia. Adverse events did not cause treatment to be stopped; a one-dose delay or dose reduction was required in $25.3 \%$ and $11.1 \%$ of patients, respectively. Due to the retrospective and multicentric nature of our study, data regarding herpes zoster and CMV infections were not satisfactory. No deaths were attributed to bendamustine treatment in the median follow-up of 22 months.

In conclusion, the present study suggests that bendamustine is a promising agent in lymphoma, both in patients with low and high-grade lymphomas as well HL who have failed multiple lines of treatments. Bendamustine may represent a valuable palliative option providing high PFS rates and a reasonable option for bridging to SCT. It is important to note that OS rates were higher than PFS rates, which is also a success of bendamustine treatment since it allows further treatment beyond bendamustine, and as a bridge therapy to other treatments and SCT. However, due to its heterogeneity and retrospective nature, the power of the present study may be limited, which further clarifies the need for prospective studies.

\section{Acknowledgments}

We thank our patients and their families who participated in the research helpfully and devotedly without expecting material compensation.

\section{Conflict of interest}

The authors declare no conflict of interest.

\section{References}

1. Anderson T, Chabner BA, Young RC, et al. Malignant lymphoma. 1. The histology and staging of 473 patients at the National Cancer Institute. Cancer 1982; 50: 2699-707.

2. Pfreundschuh M, Trümper L, Osterborg A, et al. CHOPlike chemotherapy plus rituximab versus CHOP-like chemotherapy alone in young patients with good-prognosis diffuse large-B-cell lymphoma: a randomised controlled trial by the MabThera International Trial (MInT) Group. Lancet Oncol 2006; 7: 379-91.

3. Schmitz N, Pfistner B, Sextro M, et al. Aggressive conventional chemotherapy compared with high-dose chemotherapy with autologous haemopoietic stem-cell transplantation for relapsed chemosensitive Hodgkin's disease: a randomised trial. Lancet 2002; 359: 2065-71.

4. Tageja N. Bendamustine: safety and efficacy in the management of indolent non-Hodgkins lymphoma. Clin Med Insights Oncol 2011; 5: 145-56.

5. Leoni LM. Bendamustine: rescue of an effective antineoplastic agent from the mid-twentieth century. Semin Hematol 2011; 48 (Suppl 1): S4-11.

6. Knauf WU, Lissichkov T, Aldaoud A, et al. Phase III randomized study of bendamustine compared with chlorambucil in previously untreated patients with chronic lymphocytic leukemia. J Clin Oncol 2009; 27: 4378-84.

7. Robinson KS, Williams ME, van der Jagt RH, et al. Phase II multicenter study of bendamustine plus rituximab in patients with relapsed indolent B-cell and mantle cell non-Hodgkin's lymphoma. J Clin Oncol 2008; 26: 4473-9. 
8. Vacirca JL, Acs PI, Tabbara IA, et al. Bendamustine combined with rituximab for patients with relapsed or re fractory diffuse large B cell lymphoma. Ann Hematol 2014; 93: 403-9.

9. Penne M, Sarraf Yazdy M, Nair KS, Cheson BD. Extended follow-up of patients treated with bendamustine for lymphoid malignancies. Clin Lymphoma Myeloma Leuk 2017; 17: 637-44.

10. Corazzelli G, Angrilli F, D’Arco A, et al. Efficacy and safety of bendamustine for the treatment of patients with recurring Hodgkin lymphoma. Br J Haematol 2013; 160: 207-15

11. Ghesquieres H, Stamatoullas A, Casasnovas O, et al. Clinical experience of bendamustine in relapsed or refractory Hodgkin lymphoma: a retrospective analysis of the French compassionate use program in 28 patients. Leuk Lymphoma 2013; 54: 2399-404.

12. Ohmachi K, Ando K, Ogura M, et al. Multicenter phase II study of bendamustine for relapsed or refractory indolent B-cell non-Hodgkin lymphoma and mantle cell lymphoma. Cancer Sci 2010; 101: 2059-64.

13. Weidmann E, Kim SZ, Rost A, et al. Bendamustine is effective in relapsed or refractory aggressive non-Hodgkin's lymphoma. Ann Oncol 2002; 13: 1285-9.

14. Rigacci L, Puccini B, Cortelazzo S, et al. Bendamustine with or without rituximab for the treatment of heavily pretreated non-Hodgkin's lymphoma patients: a multicenter retrospective study on behalf of the Italian Lymphoma Foundation (FIL). Ann Hematol 2012; 91: 1013-22.

15. Walter E, Schmitt T, Dietrich S, et al. Rituximab and bendamustine in patients with CD20+ diffuse large B-cell lymphoma not eligible for cyclophosphamide, doxorubicin, vincristine and prednisone-like chemotherapy. Leuk Lymphoma 2012; 53: 2290-2.

16. Horn J, Kleber M, Hieke S, et al. Treatment option of bendamustine in combination with rituximab in elderly and frail patients with aggressive B-non-Hodgkin lymphoma: rational, efficacy, and tolerance. Ann Hematol 2012; 91: 1579-86.

17. Ohmachi K, Niitsu N, Uchida T, et al. Multicenter phase II study of bendamustine plus rituximab in patients with relapsed or refractory diffuse large B-cell lymphoma. J Clin Oncol 2013; 31: 2103-9.

18. Moskowitz AJ, Hamlin PA Jr, Perales MA, et al. Phase II study of bendamustine in relapsed and refractory Hodgkin lymphoma. J Clin Oncol 2013; 31: 456-60.

19. Kharfan-Dabaja MA, Hamadani M, Sibai H, Savani BN. Managing Hodgkin lymphoma relapsing after autologous hematopoietic cell transplantation: a not-so-good cancer after all! Bone Marrow Transplant 2014; 49: 599-606.

20. Lissitchkov T, Arnaudov G, Peytchev D, Merkle K. Phase-I/II study to evaluate dose limiting toxicity, maximum tolerated dose, and tolerability of bendamustine $\mathrm{HCl}$ in pre-treated patients with B-chronic lymphocytic leukaemia (Binet stages B and C) requiring therapy. J Cancer Res Clin Oncol 2006; 132: 99-104.

21. Bergmann MA, Goebeler ME, Herold M, et al. Efficacy of bendamustine in patients with relapsed or refractory chronic lymphocytic leukemia: results of a phase I/II study of the German CLL Study Group. Haematologica 2005; 90: 1357-64.

22. Kahl BS, Bartlett NL, Leonard JP, et al. Bendamustine is effective therapy in patients with rituximab-refractory, indolent B-cell non-Hodgkin lymphoma: results from a Multicenter Study. Cancer 2010; 116: 106-14.
23. Van der Jagt R. Bendamustine for indolent non-Hodgkin lymphoma in the front-line or relapsed setting: a review of pharmacokinetics and clinical trial outcomes. Expert Rev Hematol 2013; 6: 525-537.

24. Rummel M, Kaiser U, Balser C, et al. Bendamustine plus rituximab versus fludarabine plus rituximab for patients with relapsed indolent and mantle-cell lymphomas: a multicentre, randomised, open-label, non-inferiority phase 3 trial. Lancet Oncol 2016; 17: 57-66.

25. Matsumoto K, Takayama N, Aisa Y, et al. A phase II study of bendamustine plus rituximab in Japanese patients with relapsed or refractory indolent B-cell non-Hodgkin lymphoma and mantle cell lymphoma previously treated with rituximab: BRB study. Int J Hematol 2015; 101: 554-62.

26. Salar A, Domingo-Domenech E, Panizo C, et al. Longterm results of a phase II study of rituximab and bendamustine for mucosa-associated lymphoid tissue lymphoma. Blood 2017; 130: 1772-4.

27. Cheson BD, Friedberg JW, Kahl BS, et al. Bendamustine produces durable responses with an acceptable safety profile in patients with rituximab-refractory indolent non-Hodgkin lymphoma. Clin Lymphoma Myeloma Leuk 2010; 10: 452-7. 